\title{
Global Positioning System Total Electron Content Variation over King Sejong Station in Antarctic under the Solar Minimum Condition Between 2005 and 2009
}

\author{
Jong-Kyun Chung $^{1 \dagger}$, Geonhwa Jee ${ }^{2}$, and Chi-Na Lee ${ }^{1}$ \\ ${ }^{1}$ Space Science Division, Korea Astronomy and Space Science Institute, Daejeon 305-348, Korea \\ ${ }^{2}$ Division of Polar Climate Research, Korea Polar Research Institute, Incheon 406-840, Korea
}

The total electron content (TEC) using global positioning system (GPS) is analyzed to see the characteristics of ionosphere over King Sejong station (KSJ, geographic latitude $62^{\circ} 13^{\prime}$ S, longitude $58^{\circ} 47^{\prime} \mathrm{W}$, corrected geomagnetic latitude $48^{\circ}$ S) in Antarctic. The GPS operational ratio during the observational period between 2005 and 2009 is $90.1 \%$. The annual variation of the daily mean TEC decreases from January 2005 to February 2009, but increase from the June 2009. In summer (December-February), the seasonal mean TEC values have the maximum of $26.2 \pm 2.4$ TEC unit (TECU) in 2005 and the minimum of $16.5 \pm 2.8 \mathrm{TECU}$ in 2009, and the annual differences decrease from 3.0 TECU (2005-2006) to 1.4 TECU (2008-2009). However, on November 2010, it significantly increases to 22.3 \pm 2.8 TECU which is up to 5.8 TECU compared with 2009 in summer. In winter (June-August), the seasonal mean TEC slightly decreases from $13.7 \pm 4.5$ TECU in 2005 to $8.9 \pm 0.6 \mathrm{TECU}$ in 2008 , and the annual difference is constantly about 1.6 TECU, and increases to $10.3 \pm 1.8 \mathrm{TECU}$ in 2009. The annual variations of diurnal amplitude show the seasonal features that are scattered in summer and the enhancements near equinoxes are apparent in the whole years. In contrast, the semidiurnal amplitudes show the disturbed annual peaks in winter and its enhancements near equinoxes are unapparent. The diurnal phases are not constant in winter and show near 12 local time (LT). The semidiurnal phases have a seasonal pattern between 00 LT and 06 LT. Consequently, the KSJ GPS TEC variations show the significant semidiurnal variation in summer from December to February under the solar minimum between 2005 and 2009. The feature is considered as the Weddell Sea anomaly of larger nighttime electron density than a daytime electron density that has been observed around the Antarctica peninsula.

Keywords: global positioning system, total electron content, ionosphere, Weddell Sea anomaly

\section{INTRODUCTION}

Understanding of long-term electron density variation is very important in ionospheric forecasting and nowcasting modeling for improving the accuracies of positioning and navigation of single frequency global positioning system (GPS) users because the ionospheric range delay is the largest error source in GPS after selective availability was turned off in May 2000. The electron density affecting GPS high accuracy products show significant temporal and spatial variations with year, season, month, and lo- cal time which results from changes in the solar extreme ultraviolet (EUV) and X-ray radiation, and from various chemical and dynamic processes with thermosphere and magnetosphere. Especially, the GPS ionospheric delay error in polar region is large because an accessible GPS network is limited and its composed GPS sites are few (Jee et al. 2010).

The electron density variations in polar region have been mostly studied to investigate the coupling processes of ionosphere-magnetosphere in Arctic, but in Antarctic few of ionospheric measurements are only made during

(c) This is an Open Access article distributed under the terms of the Creative Commons Attribution Non-Commercial License (http://creativecommons.org/licenses/by-nc/3.0/) which permits unrestricted non-commercial use, distribution, and reproduction in any medium, provided the original work is properly cited.

Received Nov 15, 2011 Revised Nov 23, 2011 Accepted Nov 25, 2011 ${ }^{\dagger}$ Corresponding Author

E-mail: jkchung@kasi.re.kr

Tel: +82-42-865-3239 Fax: +82-42-861-5610 
the short-term period of geomagnetic storm events from radar system and satellites measurements (Kitamura et al. 2009). Moreover, the observational results for ionospheric climatology, anomalies, and various of responses to geomagnetic storms are rarely reported in the West Antarctic, especially the Antarctic Peninsula until recently. It is one of reasons that the ground-based ionospheric measurements in the Antarctic Peninsula are very sparse because of lots of problems in managing observational instruments by severe natural environments such as strong wind and blizzard.

Recently, the geodetic ground-based GPS has been widely used as a powerful measurement tool to investigate the global and regional ionospheric structures owing to its continuous, easy operation, and many of worldwide distributed receivers. The total electron content (TEC) is an integrated measurement electron density from GPS satellite with the altitude of $\sim 22,000 \mathrm{~km}$ to GPS receiver. The GPS TEC includes the electron densities in D, E, F regions, and plasmasphere along the path between GPS satellite and ground-based receiver. Although electron densities in D and $\mathrm{E}$ regions and plasmasphere contribute to the measured GPS TEC, they are much narrower regions in height and have normally lower electron density than the F region, and at the production, loss, and transport rates of electron in the $\mathrm{F}$ region can be more significant than other regions (Liu \& Gao 2004). Consequently, GPS TEC can represent the behaviors of $F$ region ionosphere.

This paper describes the first results of ionospheric variation using GPS TEC value that is calculated the dualfrequency GPS measurement at King Sejong (KSJ) Station (geographic latitude $62^{\circ} 13^{\prime} \mathrm{S}$, longitude $58^{\circ} 47^{\prime} \mathrm{W}$, corrected geomagnetic latitude $48^{\circ} \mathrm{S}$ ) at King George Island on the Antarctic Peninsula between 2005 and 2009 in condition of solar minimum. In the first section, we will describe the observational environment at KSJ and the data processing. Then we present results for yearly, seasonal, and local time variation of GPS TEC, and discuss a physical process that may be responsible for temporal variation of GPS TEC over KSJ. A final summary section is provided to conclude this paper.

\section{MEASUREMENTS}

The KSJ station on King George Island in the Antarctic Peninsula has been continuously operated the GPS site from 2005 except for tens of days due to an operational malfunction. The GPS receiver model is Ashtech UZ-12 from 1 January 2005 to 30 November 2009 and is changed into Trimble NetR-8 from 1 December 2009. No measurement days in Table 1 may be by the bad GPS signal reception due to the frozen dome condition by heavy snowy storm called blizzard that usually occurred in winter season. Fig. 1a is the picture of the KSJ GPS site and Fig. 1b

Table 1. GPS measurement statistics at King Sejong station in Antarctic between 2005 and 2009. The numbers represent no measurement days.

\begin{tabular}{|c|c|c|c|c|c|c|c|c|c|c|c|c|}
\hline & \multicolumn{3}{|c|}{ Summer } & \multicolumn{3}{|c|}{ Fall } & \multicolumn{3}{|c|}{ Winter } & \multicolumn{3}{|c|}{ Spring } \\
\hline & Dec & Jan & Feb & Mar & Apr & May & Jun & Jul & Aug & Sep & Oct & Nov \\
\hline 2005 & 0 & 0 & 0 & 0 & 0 & 0 & 30 & 2 & 0 & 0 & 0 & 0 \\
\hline 2006 & 0 & 3 & 0 & 0 & 0 & 18 & 16 & 0 & 2 & 13 & 0 & 0 \\
\hline 2007 & 0 & 0 & 0 & 0 & 0 & 0 & 0 & 0 & 0 & 0 & 0 & 0 \\
\hline 2008 & 0 & 0 & 2 & 2 & 0 & 0 & 6 & 0 & 2 & 0 & 6 & 5 \\
\hline 2009 & 0 & 0 & 1 & 0 & 25 & 7 & 17 & 2 & 21 & 0 & 0 & 0 \\
\hline Total & & 6 & & & 52 & & & 98 & & & 24 & \\
\hline
\end{tabular}

GPS: global positioning system.
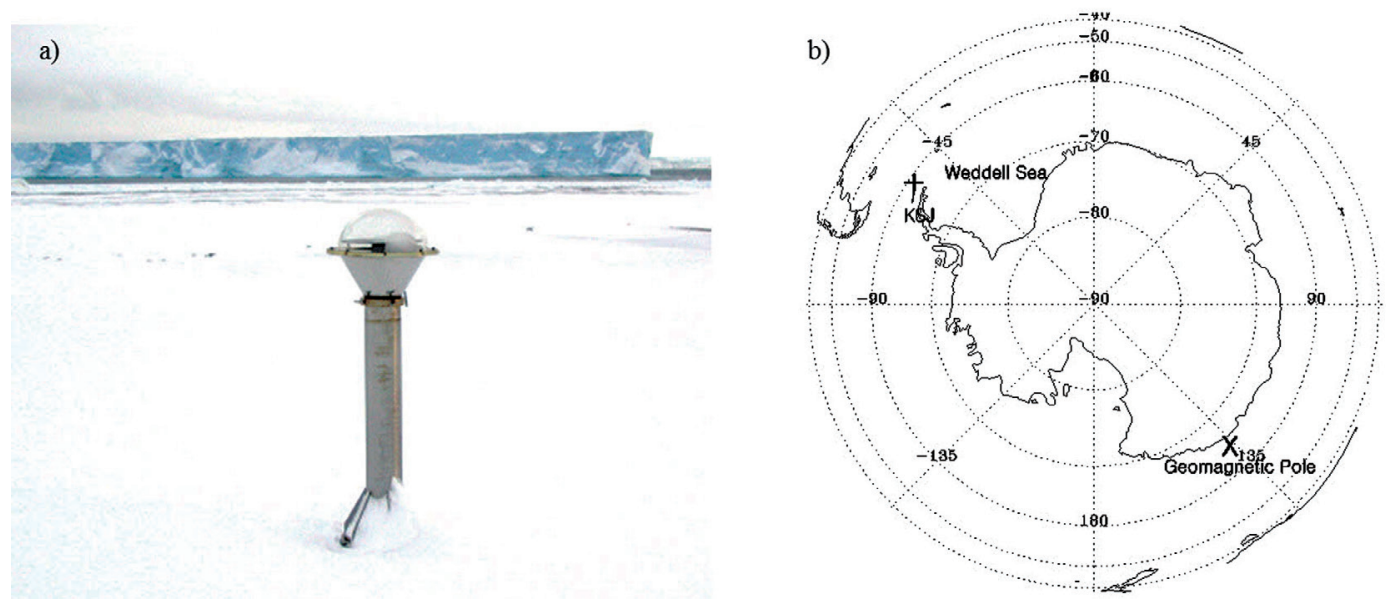

Fig. 1. a) The global positioning system antenna at King Sejong station in Antarctic and b) Location of King Sejong station (KSJ) and geomagnetic pole on the geographic map. 
shows the KSJ location on geographic map. Its geographic latitude and longitude are $62^{\circ} 13^{\prime} \mathrm{S}$ and $58^{\circ} 47^{\prime} \mathrm{W}$, respectively and its geomagnetic location is corrected geomagnetic latitude of $48^{\circ} \mathrm{S}$, declination of $11^{\circ} \mathrm{E}$, inclination of $55^{\circ}$, and L-value of 2.6 that are computed by international geomagnetic reference field-11 model. Although KSJ is geographically located at high latitude near the Weddell Sea, its geomagnetic location is mid-latitude of outer region of aurora oval.

The arrival time to GPS receiver of two L-band frequen$\operatorname{cies}\left(f_{1}=1,575.42 \mathrm{MHz}\right.$ and $\left.f_{2}=1,227.60 \mathrm{MHz}\right)$ transmitted from GPS satellite is normally delayed because the electromagnetic waves are refracted in the ionosphere. The ionospheric range delay, $\Delta R$ by the arrival time delay is proportional to slant TEC (STEC) along the path length of the radio wave and inversely proportional to square of the carrier wave frequencies of $f_{1}$ and $f_{2}$, which can be expressed as Eq. (1). The minus sign is used for carrier phase measurement and the plus sign is applied for pseudorange measurement (Liu \& Gao 2004).

$$
\Delta R= \pm 40.3 \frac{\text { STEC }}{f^{2}}
$$

The STEC can be computed by Eq. (2) using Eq. (1) and pseudorange measurements of $R_{1}$ and $R_{2}$ from two different frequencies of $f_{1}$ and $f_{2}$, respectively.

$$
S T E C=\frac{1}{40.3} \frac{f_{1}^{2} f_{2}^{2}}{f_{2}^{2}-f_{1}^{2}}\left(R_{1}-R_{2}\right)=9.52 \times 10^{16}\left(R_{1}-R_{2}\right)
$$

The STEC estimation with GPS pseudorange measurements has an uncertainty because of the high noise level of the pseudorange. In contrast, the noise of carrier phase shows significantly lower values than pseudorange ones.

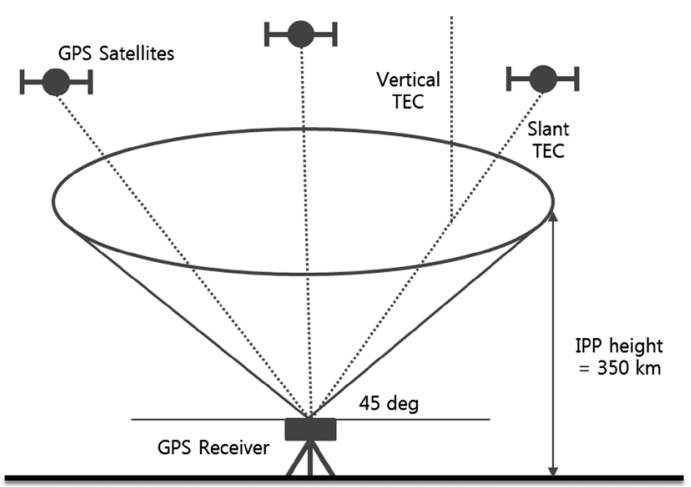

Fig. 2. Schematic diagram for King Sejong (KSJ) global positioning system (GPS) total electron content (TEC) determination. The KSJ GPS TEC is averaged with vertical TEC values at ionospheric pierce point (IPP) location above $45^{\circ}$ of elevation angle per 30 seconds.
So, we smoothed GPS pseudorange data with carrier phase measurements to reduce the pseudorange noise on STEC. The $R_{1}$ and $R_{2}$ in Eq. (2) are the corrected pseudorange values that are smoothed with carrier phase and instrument bias is removed with differential code bias neglecting multipath and receiver noise errors (Choi et al. 2011).

Global and regional GPS TEC maps have been generally used to examine the spatial morphology of ionospheric variation in case of geomagnetic disturbances or to correct the ionospheric time delay error for single frequency GPS users. However, it is not proper to investigate the ionospheric variation using single GPS receiver because its measurement points are deficit to construct the TEC map with high time resolution less than 1 hour. So, the new method is needed to monitor GPS TEC at single site. Fig. 2 shows the schematic diagram for the GPS TEC estimation at single site. We define this method as GPS TEC conical model (GTCM). The GTCM is based on single layer geometry model that assumes all free electrons are concentrated in a shell of infinitesimal thickness. In Fig. 2 , the ionospheric pierce point (IPP) is point where the ling-of-sight between the satellite and the ground receiver intersects this shell, and IPP height is typically set to expected height of the maximum electron density. We assume that IPP height where STEC is converted to vertical TEC is $350 \mathrm{~km}$ (Liu \& Gao 2004), and set the satellite mask elevation angle of $45^{\circ}$ to reduce the horizontal gradient of electron density by precipitating electrons in auroral region considering the location of the KSJ station that is shown in Fig. 1.

\section{RESULTS AND DISCUSSION}

While the satellite observations can globally cover the wide area but not the local time variation yet, the groundbased instruments have an advantage to continuously measure the ionospheric variation over a certain location with high temporal resolution. In order to see the ionospheric features over KSJ station near the Antarctic Peninsula under solar minimum condition, we analyzed the KSJ GPS TEC dataset of 1,644 days between 1 January 2005 and 30 November 2009 with exception of 181 days when the operation was disrupted by electric power failure, instrumental malfunction, and dome frozen by blizzard. The KSJ GPS operational ratio during the dataset period is $90.1 \%$, which is sufficient to examine the ionospheric variation with high temporal resolution. In this study, the KSJ GPS TEC with local time is quantita- 
tively analyzed by simple harmonic model with year. The parameters that are computed from this model can contribute to construct an empirical ionospheric model for Antarctic Peninsula and then can be applied in the area of space weather and ionospheric error correction in space navigation system if more data are accumulated and analyzed in the future.

We construct the simply model using the KSJ GPS TEC dataset with the harmonic function with two periods of Eq. (3) considering the diurnal and semidiurnal variation. The diurnal variation usually represents the electron density variation by solar EUV and X-ray radiation fluxes and the semidiurnal variation characterizes atmospheric semidiurnal tidal wave that significantly affects ionosphere by dynamical variations in the neutral wind, temperature, and chemical composition in polar region

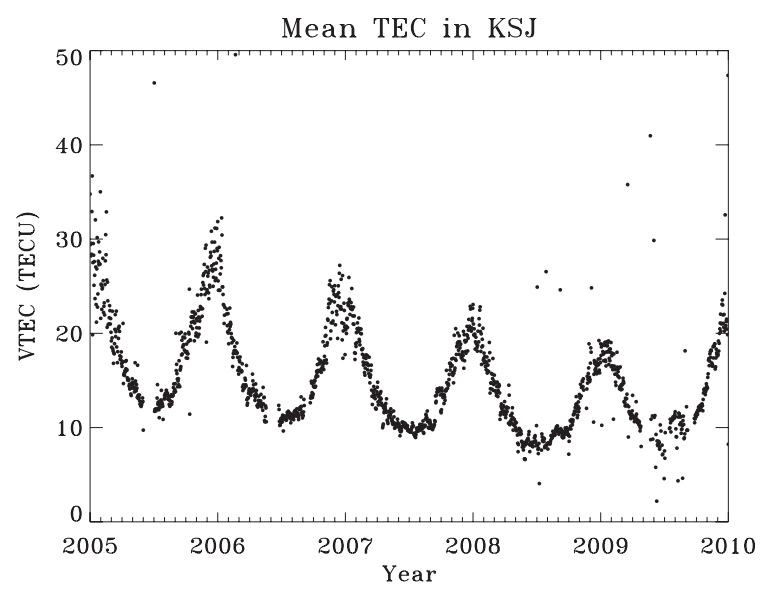

Fig. 3. Global positioning system total electron content variation over King Sejong station in Antarctic between 2005 and 2009.

Table 2. Coefficient and variables of the model function.

\begin{tabular}{ll}
\hline$E_{\text {TEC }}$ & $=$ fitted TEC \\
$t$ & $=$ local time \\
$\omega_{24 \mathrm{~h}}$ & $=2 \pi / 24$ hour \\
$\omega_{12 \mathrm{~h}}$ & $=2 \pi / 12$ hour \\
$a_{0}$ & $=$ daily mean \\
$a_{1}$ and $a_{2}$ & $=$ amplitude and phase of diurnal variation \\
$\mathrm{a}_{3}$ and $\mathrm{a}_{4}$ & $=$ amplitude and phase of semi-diurnal variation \\
\hline TEC: total electron content.
\end{tabular}

Table 3. Seasonal mean TEC in summer (December-February) and winter (June-August).

\begin{tabular}{lcccccc}
\hline & 2005 & 2006 & 2007 & 2008 & 2009 & Dec. 2009 \\
\hline Summer & $26.2 \pm 2.4$ & $23.2 \pm 4.2$ & $20.5 \pm 2.5$ & $17.9 \pm 2.6$ & $16.5 \pm 2.8$ & $22.3 \pm 1.8$ \\
Winter & $13.7 \pm 4.5$ & $11.9 \pm 4.9$ & $10.1 \pm 0.4$ & $8.9 \pm 0.6$ & $10.3 \pm 1.8$ & - \\
\hline TEC: &
\end{tabular}

TEC: total electron content.
(Nozawa et al. 2010). The semidiurnal term can also represent the abrupt changes of electron density in case of geomagnetic disturbances in nighttime.

$$
T E C_{f i t}=a_{0}+a_{1} \cos \left[\omega_{d}\left(t-a_{2}\right)\right]+a_{3} \cos \left[\omega_{s d}\left(t-a_{4}\right)\right]
$$

In Eq. (3), the $T E C_{f i t}$ is the GPS TEC value that is fitted using the harmonic function with the period of the 24hour and 12-hour. The five parameters $a_{0}, a_{1}, a_{2}, a_{3}$, and $a_{4}$ are the coefficients to be adjusted for curved least square fitting to the measured daily GPS TEC data. The coefficients and variables of the curved fitting function and their meanings are listed in Table 2 . These values can give the quantitative values in the ionospheric temporal variation and is based to empirically model the GPS TEC variation in the future. In this work, we analyze the coefficients to examine the ionospheric temporal variation at KSJ station.

Fig. 3 shows the annual variation of the daily mean TEC, $a_{0}$ between 1 January 2005 and 30 November 2009 in solar minimum condition. The $a_{0}$ continuously decreases from January 2005 to summer between December in 2008 and February in 2009, but begins to increase from the winter between June and August 2009. Considering the GPS TEC variation typically depends upon solar EUV and $\mathrm{X}$-ray radiation fluxes, it can indicate that the increasing phase of the solar activity begins from the winter 2009 in the southern hemisphere. Table 3 gives the seasonal mean TEC, the averaged $\mathrm{a}_{0}$ in summer and winter. In long day summer (December-February), the seasonal mean TEC values have the maximum of $26.2 \pm 2.4$ TEC unit (TECU) in 2005 and the minimum of $16.5 \pm 2.8$ TECU in 2009, and the annual differences decrease from 3.0 TECU (2005-2006) to 1.4 TECU (2008-2009). However, on November 2009, it suddenly increases to $22.3 \pm 2.8$ TECU which is up to 5.8 TECU compared with 2009 in summer. Although the dataset for the full solar cycle of 11 years is needed to study the GPS TEC variation according to solar activities, it shows the increasing TEC ratio is higher than the decreasing TEC ratio. This result may be a natural tendency of the ionospheric electron density variations with solar activity since the initial phase increasing phase of the solar cycle is normally faster than the declining phase of the solar cycle. In long winter night (June-August), the seasonal mean TEC slightly decreases from $13.7 \pm 4.5$ TECU in 2005 to $8.9 \pm 0.6$ TECU in 2008 , and the annual difference is constantly about $1.6 \mathrm{TECU}$, and increases to $10.3 \pm 1.8$ TECU in 2009 .

Fig. 4 presents the variation of the $a_{1}$ (upper panel) and $a_{3}$ (lower panel) of diurnal and semi-diurnal amplitudes 
with year, respectively. The variations of diurnal amplitude, $a_{1}$ with years show the seasonal features but the greatly dispersed features in summer. The $\mathrm{a}_{1}$ in summer is even lower than the value of winter in some days. A little unapparent diurnal variation of KSJ GPS TEC in the summer may be not changed by solar radiation. In contrast, the semidiurnal amplitudes, $\mathrm{a}_{3}$ show the clear peak near December solstice and its enhancements near equinoxes are not apparent. It indicates that the semidiurnal variation is the main feature in summer at KSJ station. The phases of diurnal and semidiurnal amplitude are presented in Fig. 5. The diurnal phases show the significant seasonal oscillation between 12 local time (LT) and 18 LT but are also dispersed in winter season. The semidiurnal phases show between $00 \mathrm{LT}$ and $06 \mathrm{LT}$ and then gradually move with month. It indicates the semidiurnal varia-

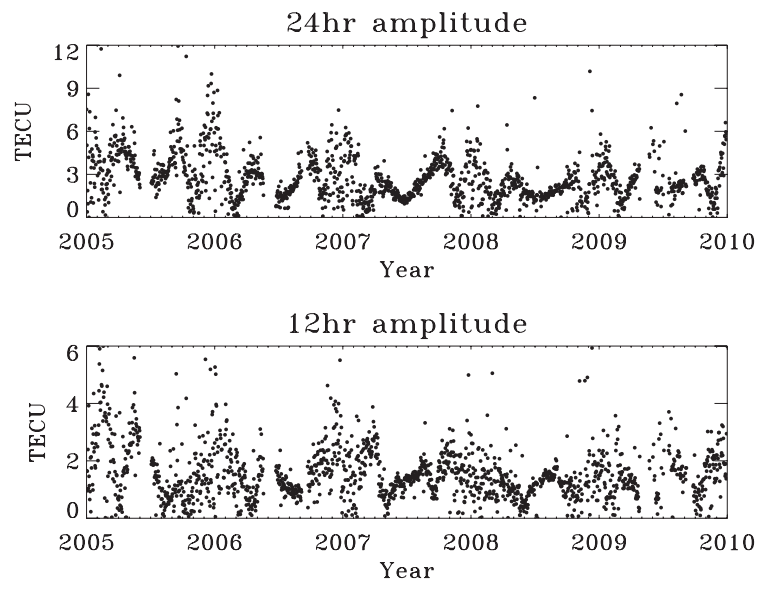

Fig. 4. The diurnal and semidiurnal amplitudes of global positioning system total electron content variation at King Sejong station between 2005 and 2009.
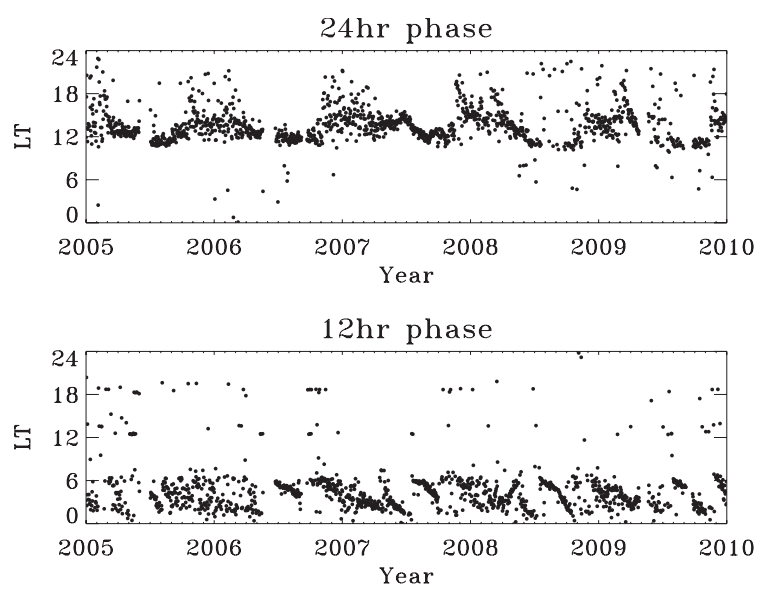

Fig. 5. The diurnal and semidiurnal phases of global positioning system total electron content variation at King Sejong station between 2005 and 2009. tion is depend upon the month, and may be triggered by a regular variation of thermospheric neutral wind, geomagnetic field configuration, or aurora activities besides of ionization by solar radiation. It is needed to analyze with the theoretical model and other measurements.

In solar minimum condition between 2005 and 2009, the GPS TEC variations over KSJ station near the Antarctic Peninsula show the noticeable semidiurnal variations that the GPS TEC values in nighttime are higher than the daytime values in summer. The features indicate the Weddell Sea anomaly (WSA) of larger nighttime electron density than a daytime electron density that has been observed around the Antarctic Peninsula. Horvarth (2006) and Jee et al. (2009) reported the global WSA morphology and its available mechanisms using the altimetry TEC from TOPEX/Poseidon satellites. Their results for WSA show the globally spatial changes according to season, year, and solar activities. However, the evolution of the WSA with local time is not suggested yet because satellite observation has a constraint to cover the whole local time. Our study using ground-based GPS TEC measurement is expected to increase an understanding for the WSA morphology and its mechanism together with satellite measurements. In the following work, we examine the KSJ ionospheric variation using the neutral wind and geomagnetic field configuration using the model results and other measurements.

\section{SUMMARY}

In order to see the ionospheric features over KSJ station (geographic latitude $62^{\circ} 13^{\prime} \mathrm{S}$, longitude $58^{\circ} 47^{\prime} \mathrm{W}$, corrected geomagnetic latitude $48 \mathrm{~S}$ ) near the Antarctic Peninsula on the solar minimum condition, we analyzed the KSS GPS TEC dataset of 1,644 days between 1 January 2005 and 30 November 2009. The annual variation of the daily mean TEC decreases from January 2005 to February 2009, but increase from the June 2009. The variations of diurnal amplitude with years show the seasonal features but the greatly dispersed features in summer. In contrast, the semidiurnal amplitudes show the clear peak in summer. The diurnal phases show the significant seasonal oscillation between $00 \mathrm{LT}$ and $06 \mathrm{LT}$ and gradually move with month. Consequently, the GPS TEC variations over KSJ station near the Antarctic Peninsula show the noticeable semidiurnal variations in summer. It is suggested the KSJ GPS TEC may be clearly affected by the WSA of larger nighttime electron density than a daytime electron density that has been observed around the Antarctica pen- 
insula. We will further examine the local time evolution of WSA according to the year and season using extensive observation dataset such as neutral wind, more groundbased GPS TEC data.

\section{ACKNOWLEDGEMENTS}

This work was supported by a research grant at the Korea Polar Research Institute (PP11030). We thank the overwintering team having worked in KSJ station for their efforts to operate the GPS site.

\section{REFERENCES}

Choi BK, Cho JH, Lee SJ, Estimation and analysis of GPS receiver differential code biases using KGN in Korean Peninsula, AdSpR, 47, 1590-1599 (2011). http://dx.doi.org/ 10.1016/j.asr.2010.12.021

Horvarth I, A total electron content space weather study of the nighttime Weddell Sea Anomaly of 1996/1997 southern summer with TOPEX/Poseidon radar altimetry, JGR, 111,
A12317 (2006). http://dx.doi.org/10.1029/2006JA011679 Jee G, Burns AG, Kim Y-H, Wang W, Seasonal and solar activity variations of the Weddell Sea Anomaly observed in the TOPEX total electron content measurements, JGR, 114, A04307 (2009). http://dx.doi.org/10.1029/2008JA013801

Jee G, Lee H-B, Kim YH, Chung J-K, Cho J, Assessment of GPS global ionosphere map (GIM) by comparison between CODE GIM and TOPEX/Jason TEC data: Ionospheric perspective, JGR, 115, A10319 (2010). http://dx.doi.org/ 10.1029/2010JA015432

Kitamura N, Shinbori A, Nishimura Y, Ono T, Iizima M, et al., Seasonal variations of the electron density distribution in the polar region during geomagnetically quiet periods near solar maximum, JGR, 114, A01206 (2009). http://dx.doi.org/10.1029/2008JA013288

Liu Z, Gao Y, Ionospheric TEC predictions over a local area GPS reference network, GPS Solut, 8, 23-29 (2004). http://dx.doi.org/10.1007/s10291-004-0082-x

Nozawa S, Ogawa Y, Oyama S, Fujiwara H, Tsuda T, et al., Tidal waves in the polar lower thermosphere observed using the EISCAT long run data set obtained in September 2005, JGR, 115, A08312 (2010). http://dx.doi.org/ 10.1029/2009JA015237 